\title{
Sistem Informasi Customer Relationship Management Pada Hotel Grand Malaka Ethical Palembang Berbasis Web
}

\author{
Mutia Rizky Pratiwi ${ }^{1}$, Fithri Selva Jumeilah, Fathiyah Nopriani \\ TSains dan Teknologi , Universitas Islam Negeri Raden Fatah, Palembang, Idnonesia \\ 2,3Siste Informasi, Universitas Islam Negeri Raden Fatah, Palembang, Idnonesia \\ Email: 1mutiarizkypratiwi@gmail.com, 2fithriselvajumeilah@radenfatah.ac.id, \\ 3fathiyahnopriani_uin@radenfatah.ac.id
}

\begin{abstract}
Grand Malaka Ethical is a sharia hotel located in Palembang City with a three-star classification, located on Jalan Malaka II No.5. With the rapid development of technology today, many hotel booking applications that provide star-rated hotels with cheap and good prices make Hotel Grand Malaka must compete with other hotels in order not to be left behind. Grand Malaka Ethical Hotel still uses minimal applications and recently hotel visitors continue to decline. This study aims to create a web-based Customer Relationship Management Information System using the Prototype system development method. This research has produced a Web-based Customer Relationship Management Information System at the Grand Malaka Ethical Palembang Hotel that has been tested and will be implemented by the hotel in 2021 .
\end{abstract}

Keywords: Sistem Informasi, Customer Relationship Management, Prototype.

\section{PENDAHULUAN}

Pada era globalisasi saat ini, perkembangan teknologi meningkat dengan pesat. Dengan berkembangnya teknologi maka teknologi yang tekomputerisasi sangat dibutuhkan di berbagai bidang/sektor industri bahkan dibidang pariwisata khususnya pada usaha perhotelan. Hotel merupakan perusahaan akomodasi yang menyediakan penginapan, jasa layanan, makanan dan minuman yang dikelola secara komersial. Salah satu faktor yang menentukan kualitas dan tingkat keberhasilan perusahaan adalah kemampuan perusahaan dalam memberikan pelayanan dan menciptakan hubungan yang baik kepada pelanggan [1].

Grand Malaka Ethical merupakan salah satu hotel berbintang tiga di Kota Palembang, hotel ini memiliki fasilitas yang cukup lengkap seperti kolam renang,

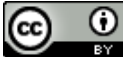

This work is licensed under a Creative Commons Attribution 4.0 International License. 
ballroom dan disertai taman untuk membuat para tamu nyaman. Selain itu hotel ini merupakan hotel syariah yang menjadikannya sebagai daya tarik para tamu untuk menginap. Akan tetapi, hotel Grand Malaka Ethical masih minim menggunakan aplikasi, data transaksi pemesanan pun tidak tersimpan dengan baik hingga menyebabkan data transaksi dibawah tahun 2017 tidak tersedia lagi, selain itu pemesanan kamar dan ballroom hotel masih dipesan dengan datang langsung kehotel.

Dengan berkembangnya teknologi hotel Grand Malaka harus bersaing dengan hotel lain agar tidak tertinggal. Apalagi sekarang sudah banyak tersedia hotelhotel berbintang dengan harga murah dan bagus yang dipasarkan melalui aplikasi penyedia hotel. Dalam menghadapi persaingan di bidang perhotelan yang semakin melonjak pesat, terutama pada Kota yang potensi wisatanya cukup tinggi, menuntut pihak manajemen hotel untuk selalu memperbaiki pelayanan dan menawarkan fasilitas terbaik dengan tujuan agar menarik pelanggan baru dan mempertahankan pelanggan lama agar tetap menjadi pelanggan setia (Customer Loyality) [2]. Grand Malaka Ethical berdiri pada tahun 2007 dengan letak lokasi yang sangat strategis, sehingga sudah memiliki jumlah pengunjung yang cukup banyak. Tetapi belakang ini pengunjung hotel terus menurun. Penurunan pengunjung hotel ini disebabkan oleh kurangnya pihak hotel dalam menjalin hubungan dengan pelanggan seperti kurangnya media untuk memberikan informasi dan promo pada hotel, lalu tidak tersedianya media untuk customer dalam menyampaikan keluhan dan masukkan untuk pihak hotel sehingga menyebabkan pihak hotel kurang memahami keinginan customer.

Cara untuk menciptakan hubungan yang baik dengan pelanggan dan meningkatkan rasa kepuasan, sehingga pelanggan mau menggunakan jasa yang diberikan secara berulang dan bahkan mampu meningkatkan jumlah pelanggan yaitu dengan menerapkan Customer Relationship Management (CRM) dengan menggunakan teknologi informasi dengan tujuan mempercepat penyampaian informasi antara pelanggan dengan perusahaan [3]. Berdasarkan permasalahan tersebut, maka penulis mengambil judul "Sistem Informasi Customer Relationship Management Pada Hotel Grand Malaka Ethical Palembang Berbasis Web." yang dapat memudahkan customer dalam melakukan pemesanan kamar 
dan ballroom, serta mempermudah pihak hotel untuk memberikan informasi terkait hotel dengan cepat dan detail kepada customer.

\section{METODOLOGI PENELITIAN}

Metode yang dipakai dalam penelitian ini yaitu metode penelitian dan metode pengembangan sistem. Adapun metode penelitian yang digunakan adalah Research and Development ( $R \& D$ ) dan untuk metode penmgembangan sistem yang digunakan adalah metode prototype.

\subsection{Metode Penelitian}

Metode penelitian yang dipakai yaitu Research and Development $(R \& D)$. Metode penelitian Research and Development $(R \& D)$ adalah metode penelitian yang dipakai untuk menghasilkan sebuah produk tertentu dan diuji keefektifannya. Untuk menghasilkan sebuah produk yang baik maka digunakan penelitian yang bersifat analisis kebutuhan dan akan diuji keefektifan produk tersebut supaya dapat berfungsi di masyarakat luas, maka diperlukan penelitian untuk menguji keefektifan produk tersebut [4]. Dari 10 langkah yang dikembangakan oleh Sugiyono. Adapun Langkah-langkah yang digunakan dalam penelitian dan pengembangan menurut Sugiyono dapat digambarkan sebagai berikut:

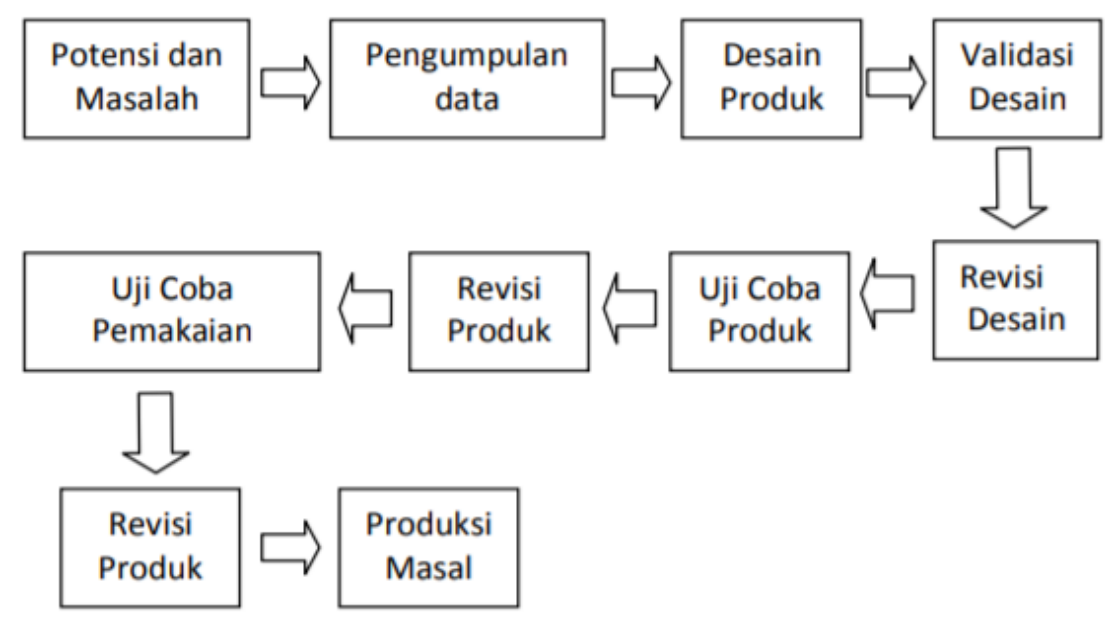

Gambar 1 Langkah Penelitian Research and Development 
berikut adalah diagram alur penelitian yang digunakan pada penelitian ini:

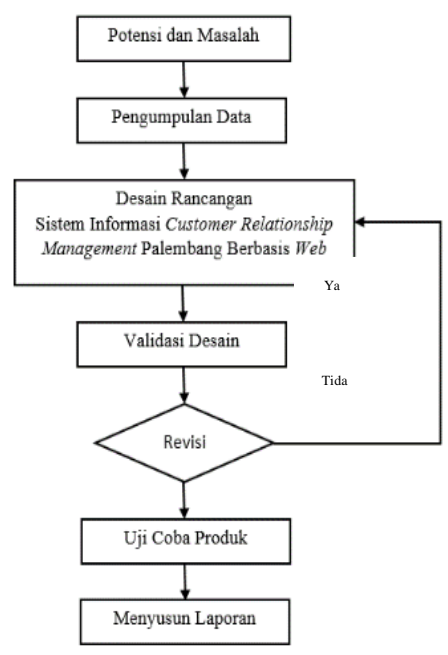

Gambar 2 Tahapan Penelitian

Berdasarkan gambar diatas, tahapan penelitian yang dilakukan oleh peneliti adalah sebagai berikut:

1. Potensi dan Masalah

Pada tahap ini peneliti mengidentifikasi potensi dan masalah yang terjadi pada Hotel Grand Malaka Ethical. Identifikasi masalah ini dilakukan agar peneliti mengetahui apa saja masalah atau kendala yang terjadi pada objek penelitian sehingga peneliti dapat melakukan perencanaan untuk memecahkan masalah tersebut.

2. Pengumpulan Data

Tahapan selanjutnya setelah identifikasi masalah adalah pengumpulan data.

Pengumpulan data pada penelitian ini dilakukan dengan cara obsevasi, wawancara dan studi pustaka. Observasi dilakukan dengan cara datang dan mengamati secara langsung alur kerja yang ada pada Hotel Grand Malaka Ethical. Lalu melakukan wawancara dengan mewawancarai secara langsung pihak Accounting hotel dan beberapa Customer atau pengunjung Hotel Grand Malaka Ethical. Sedangkan studi pustaka dilakukkan dengan mengumpulkan data-data yang berhubungan dengan penelitian melalui buku dan literature ilmiah.

3. Desain Rancangan

Tahap selanjutnya setelah melakukan pengumpulan data adalah membuat rancangan sistem. Pembuatan rancangan sistem dilakukan dengan 
membuat perancangan UML, antarmuka (interface), ERD dan struktur tabel database.

4. Validasi Desain

Tahap selanjutnya yaitu validasi desain dimana pihak accounting hotel menilai apakah rancanagan yang telah dibuat telah memenuhi keinginan dan kebutuhan pihak hotel.

5. Perbaikan Desain

Setelah desain berupa rancangan UML, antarmuka (interface), ERD, dan struktur database dievaluasi oleh accounting hotel maka menghasilkan berbagai masukan dari rancangan tersebut. Dari hasil inilah kemudian akan dilakukan beberapa perubahan yang menjadikan sistem ini sesuai keinginan dan kebutuhan hotel. Jika tidak terdapat revisi maka peneliti melanjutkan untuk menerjemahkan perancangan ke dalam bahasa pemrograman. Bahasa pemrograman yang digunakan adalah PHP yang menggunakan Framework Codelgniter. Selanjutnya peneliti melanjutkan ke langkah penelitian selanjutnya.

6. Uji Coba Produk

Setelah desain deperbaiki dan sistem telah dibuat maka selanjutnya akan dilakukan uji coba produk yang akan dilakukan oleh pihak hotel.

\subsection{Metode Pengembangan}

Pengembangan Sistem disini menggunakan beberapa tools untuk membantu analisa sistem dari Metode Prototype, berdasarkan terdapat lima proses yaitu seperti gambar di bawah ini. Model prototype dapat dilihat pada Gambar 3.3:

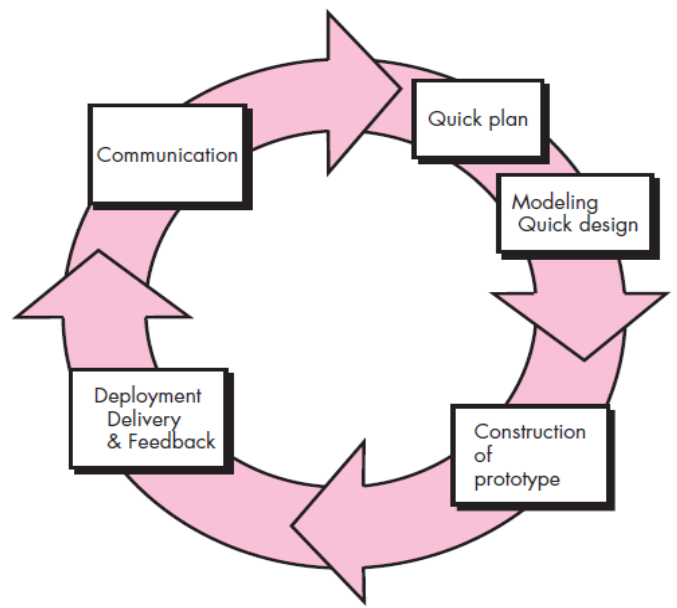

Gambar 3 Model Prototype [5] 


\section{HASIL DAN PEMBAHASAN}

1) Communication (Komunikasi)

Komunikasi adalah tahap awal dari metode prototype yang mana bertujuan agar mendapatkan gambaran dari sebuah sistem yang akan dibangun. Untuk mendapatkan data penulis menggunakan metode wawancara dan observasi.

\section{2) Quick Plan (Perencanaan Secara Cepat)}

a. Analisis Kebutuhan Fungsional

Kebutuhan fungsional mendeskripsikan tentang layanan, fitur atau fungsi yang disediakan oleh sistem untuk pengguna.

1. Sistem ini akan memberikan akses untuk setiap pengguna. Masingmasing pengguna bisa melakukan login disetiap kegiatan sesuai tugas masing-masing. Seperti e-mail dan password. Hak akses ini diberikan kepada bagian customer, front office, accounting dan manager.

2. Pada sistem ini customer bisa registrasi, memesan kamar dan ballroom, melihat dan melakukan mission, melakukan chat, menginput dan mengedit profile dan dapat melihat point serta mendaptkan reward.

3. Pada sistem ini front office bisa menginput, mengedit, menghapus dan lihat kelola data master, hak akses, membalas chat, melakukan pemesanan, melihat pemesanan, konfirmasi pembayaran, menginput dan mengedit profile.

4. Pada sistem ini accounting bisa menginput, mengedit, menghapus dan lihat data promosi atau informasi, diskon, reward, dan mission serta laporan pemesanan kamar, ballroom, dan data reward.

5. Pada sistem ini manager bisa melihat grafik presentase pemesanan kamar dan ballroom, grafik pelanggan yang sering menginap, mencetak laporan pemesanan kamar, ballroom dan data reward.

b. Analisis Kebutuhan Non-Fungsional

Analisis kebutuhan non-fungsional dalam penelitian ini adalah sebagai berikut:

a. Perangkat keras (Hardware) yang digunakan dalam penelitian yaitu sebagai berikut:

1) $P C$ (Personal Computer), dengan spesifikasi Processor Inte/(R) Core(TM) i3-3110M CPU @ 2.40GHz 2.40 GHz.

2) RAM $4 \mathrm{~GB}$.

3) Penyimpanan Hardisk 500 GB.

4) Hardisk $1 \mathrm{~TB}$

b. Perangkat lunak (Software) yang digunakan dalam penelitian yaitu sebagai berikut: 
1) Sistem operasi yaitu Windows 10 ultimate 64-bit.

2) Sublime Text 3 sebagai text editor.

3) Codeigniter sebagai framework.

4) Xampp Control Pane/v5.6.3 sebagai server yang mengintegrasikan database.

5) ArgoUML untuk membuat pemodelan.

6) Balsamiq Mockups 3 untuk membuat desain interface

7) Google chrome untuk membuka sistem.

c. Analisis Penerapan Konsep Customer Relationship Management (CRM)

Sistem yang akan dibangun pada Hotel Grand Malaka Ethical Palembang akan diterapkan konsep CRM berdasarkan 3 tahapan CRM yaitu:

1. Acquire (mendapatkan pelanggan baru)

Acquire betujuan untuk mendapatkan pelanggan baru dengan cara memeberikan kemudahan dan memberikan kesan pertama yang menarik dengan mengunjungi website hotel dengan memiliki fitur seperti news hotel yang dapat memudahkan customer dalam melihat promosi hotel, promosi penjualan berguna untuk menawarkan dan sebagai pemicu langsung untuk membeli suatu produk dan fitur Frequently Asked Question ( $F A Q)$ yang menyediakan jawaban dari pertanyaan seputar hotel yang mungkin dubutuhkan oleh customer sehingga memudahkan customer dalam menggunakan sistem.

\section{Enhance (menjalin hubungan yang baik)}

Enhance bertujuan agar menciptakan hubungan yang baik dengan customer dengan cara mendengarkan keluhan dan saran pelanggan dengan fitur kritik dan saran yang bisa diisi customer agar pihak hotel dapat memperbaiki dan meningkatkan kualitas hotel. Lalu terdapat fitur point dan reward, dimana dari point yang didapatkan bisa ditukarkan dengan reward yang tersedia, point dan reward berguna untuk membuat customer yang telah melakukan pemesanan merasa senang sehingga terciptanya rasa kepuasan dan terdapat fitur chat agar customer dengan mudah berdialog dengan pihak hotel untuk bertanya secara langsung sesuatu yang membuat mereka bingung agar cepat terjawab.

3. Retain (mempertahankan pelanggan),

Retain bertujuan agar menciptakan kesetiaan atau loyalitas pelanggan sehingga menciptakan hubungan yang saling menguntungkan dengan adanya fitur mission yang berguna untuk menarik pelanggan untuk melakukan pemesanan 
secara berulang agar dapat menyelesaikan mission yang tersedia dan mengklaim hadiah yang didapatkan dari menyelesaikan mission tersebut. Lalu dengan terdaftarnya customer maka customer sudah dianggap menjadi member hotel yang akan mendapatkan e-mail apabila hotel sedang memberikan promo ataupun diskon.

\section{3) Modeling (Perancangan)}

Pada tahapan ini dilakukan analisis dan pemodelan pada sistem yang akan di bangun.

\section{A. Use Case Diagram}

Use case pada sistem ini terdapat 4 aktor yaitu customer, front office, accounting, dan manager yang mana pada setiap actor terdapat interaksinya masing-masing.

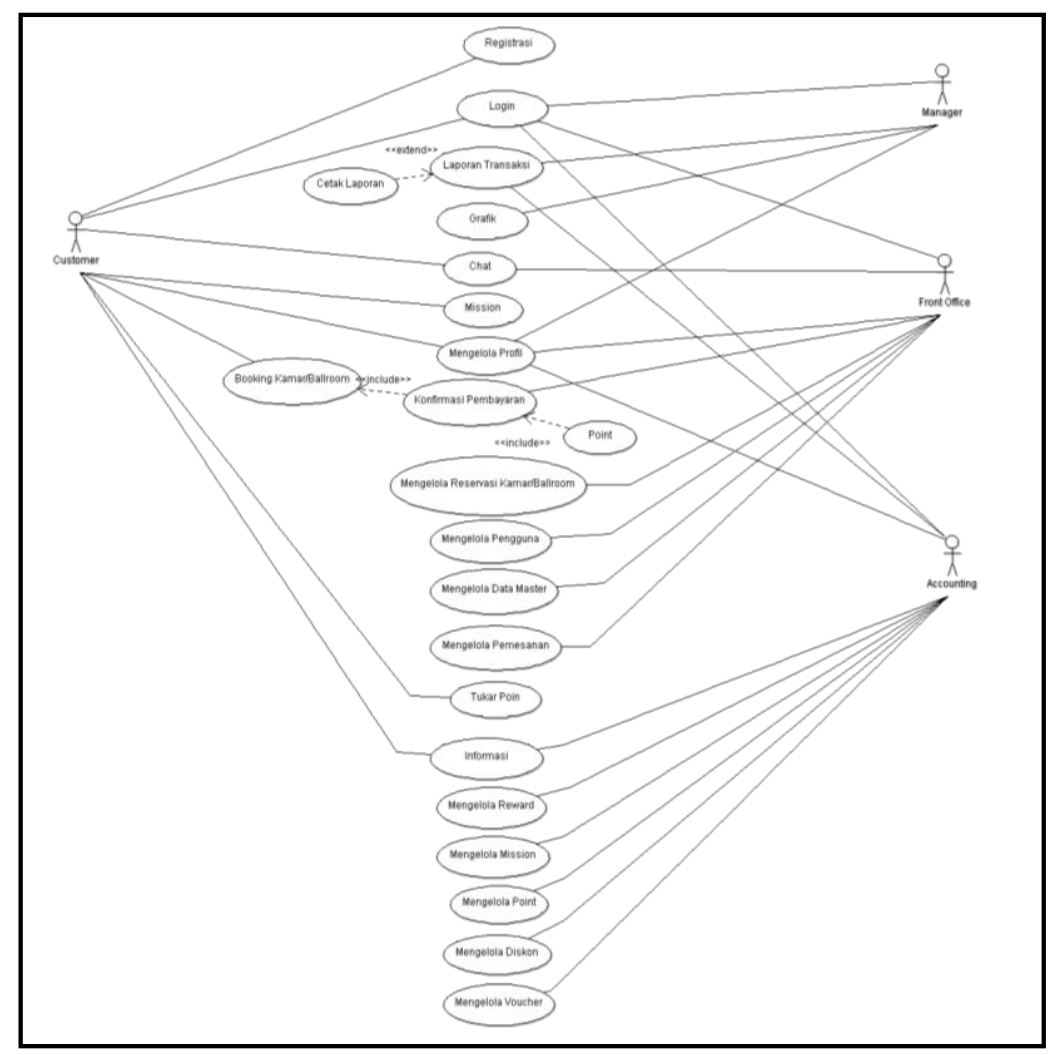

| Gambar 4. Use Case Diagram 


\section{B. Activity Diagram}

Activity diagram digunakan untuk menggambarkan fungsi-fungsi dari sistem yang akan di bangun. Pada tahapan ini digambarkan dengan menggunakan activity diagram yang dapat dilihat pada gambar berikut:
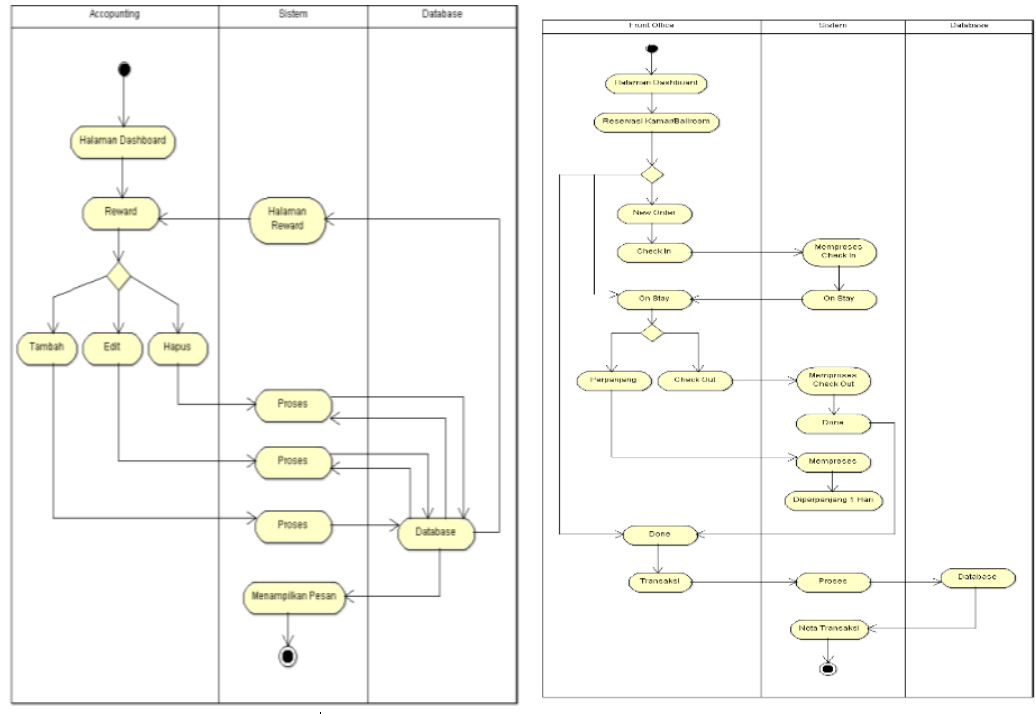

| Gambar 5 Activity Diagram

\section{Class Diagram}

Class diagram digunakan untuk menggambarkan kelas kelas yang ada pada sistem yang akan di bangun. Pada tahapan ini digambarkan dengan menggunakan Class diagram yang dapat dilihat pada gambar berikut:

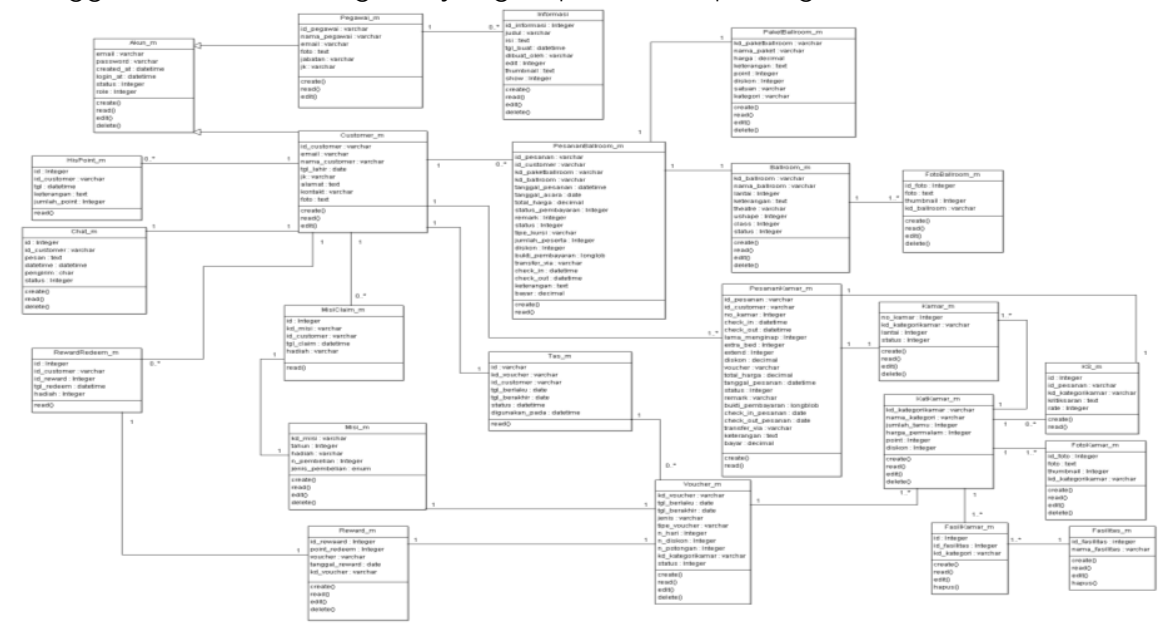

Gambar 6. Class Diagram 
D. Perancangan Antarmuka (interface)

1. Rancangan Halaman Login

Pada rancangan halaman login menyediakan tampilan login. Pengguna yang menggunakan sistem ini adalah customer, front office, accounting, dan manager, yang akan diberi wewenang sesuai hak akses masing-masing. Rancangan login bisa dilihat di Gambar 7 berikut:

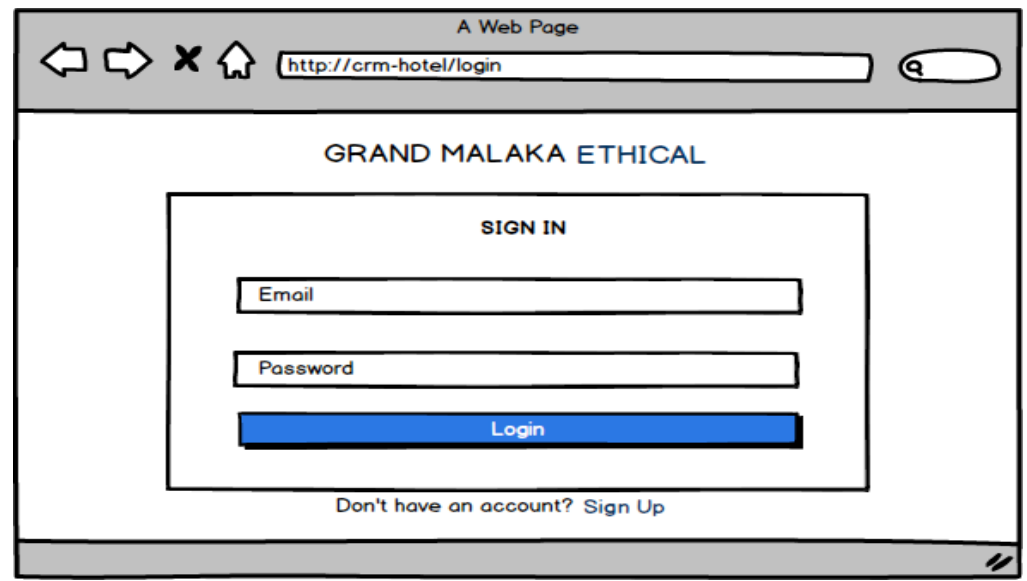

Gambar 7 Rancangan Halaman Login

\section{Rancangan Halaman Dashboard Customer}

Pada rancangan halaman dashboard customer menyediakan tampilan promo, kategori kamar dan ballroom, Rancangan Dashboard Customer bisa dilihat di Gambar 8 berikut:

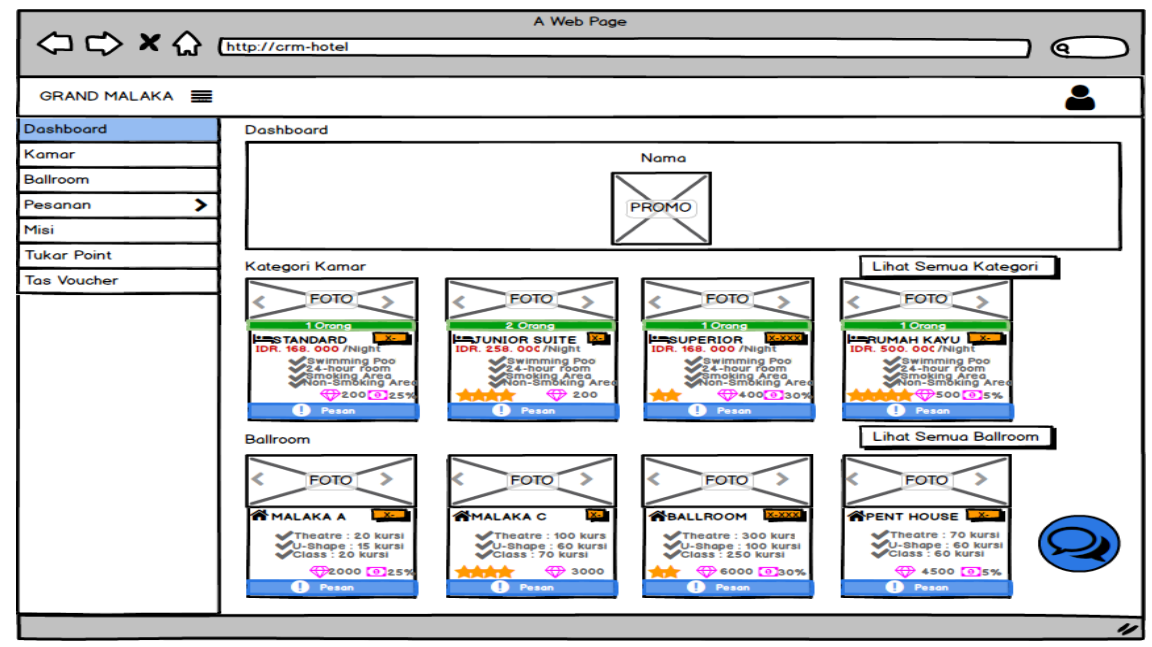

Gambar 8 Rancangan Halaman Dashboard Customer 


\section{Rancangan Halaman Kamar}

Pada rancangan halaman kamar menyediakan tampilan pilihan kamar yang tersedia. Rancangan Kamar bisa dilihat di Gambar 9 berikut:

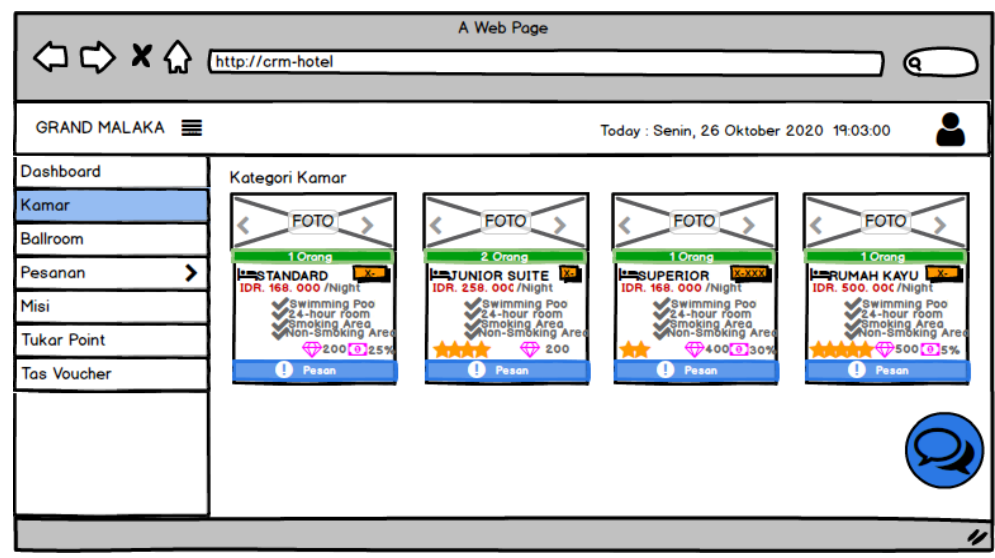

Gambar 9 Rancangan Halaman Kamar

\section{4) Construction (Kontruksi)}

Setelah melakukan analisis masalah dan perancangan, maka selanjutnya dilakukan tahapan kontruksi. Proses ini dilakukan dengan melakukan pengkodean atau pembangunan sistem menggunakan bahasa pemrograman tertentu yang dibuat sesuai dengan rancangan yang telah dibuat sebelumnya.

1. Halaman Login

Login merupakan halaman untuk customer, front office, accounting, dan manager untuk masuk ke dalam sistem dan mengakses fitur-fitur yang ada di sistem, yang telah diberi wewenang sesuai hak akses masing-masing. Berikut tampilan-tampilan sistem yang telah dibangun. Halaman login bisa dilihat di Gambar 10 berikut:

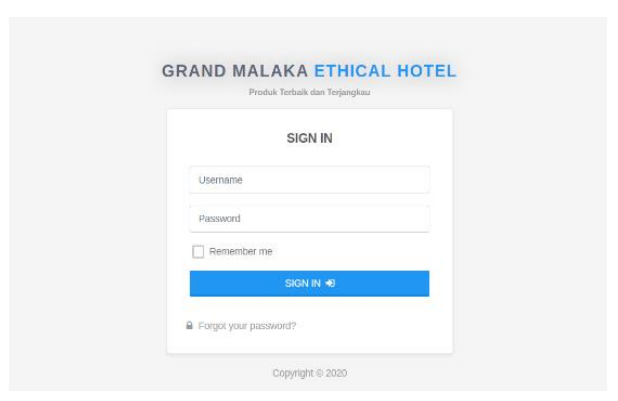

Gambar 10 Halaman Login 
2. Implementasi Halaman Dashboard Customer

Implementasi Halaman dashboard customer bisa dilihat di Gambar 11 berikut:

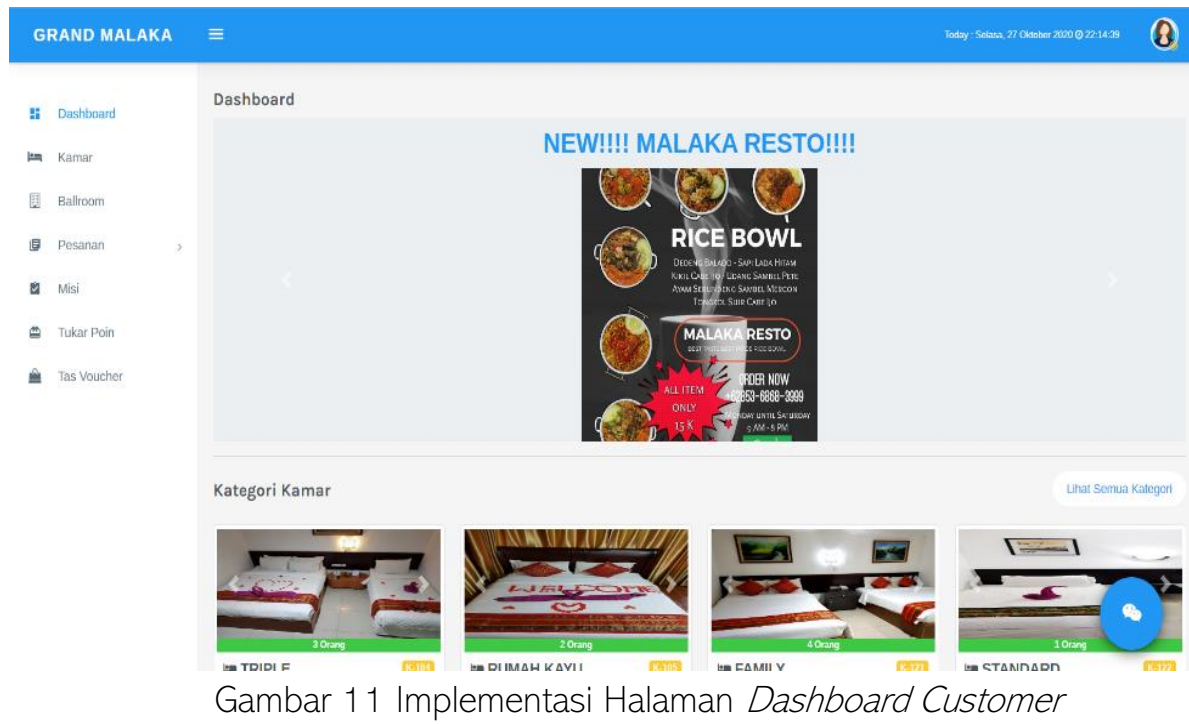

3. Implementasi Halaman Kamar

Implementasi halaman kamar tersedia tampilan pilihan kamar. Implementasi halaman kamar bisa dilihat di Gambar 12 berikut:
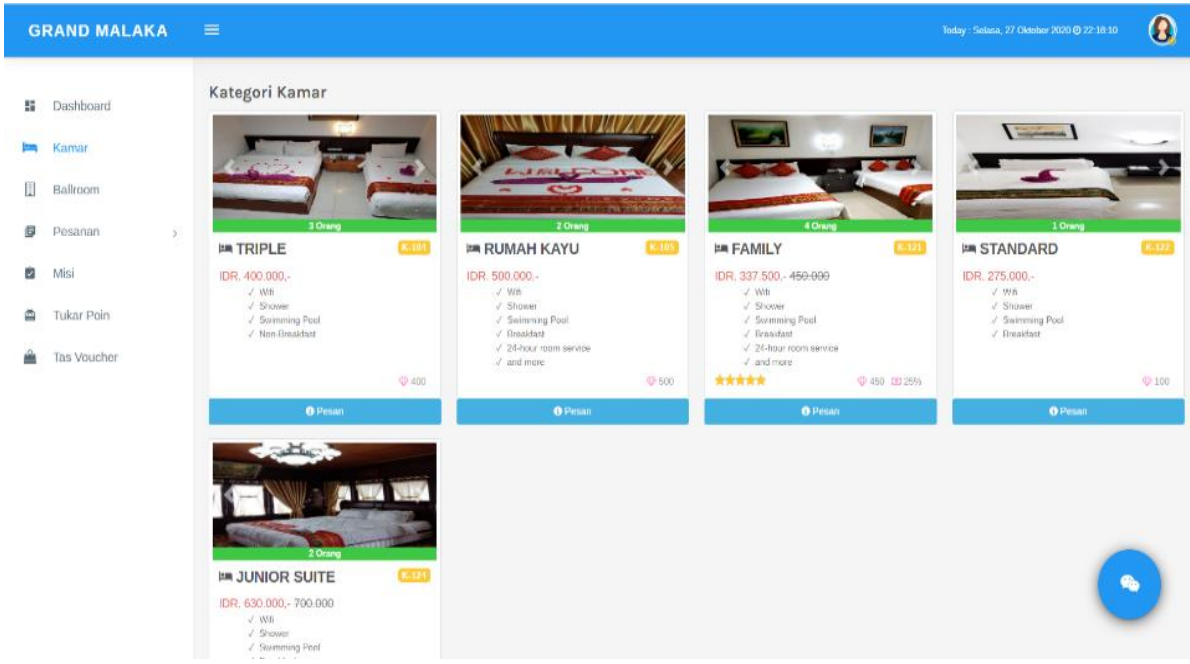

Gambar 12 Implementasi Halaman Kamar 
4. Implementasi Halaman Ballroom

Implementasi halaman ballroom bisa dilihat di Gambar 13 berikut:
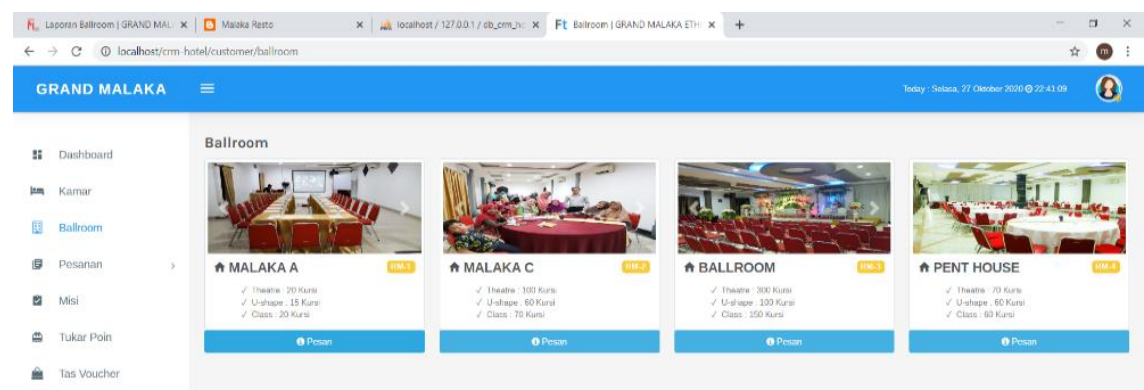

Ballroom

a) Dashboant

kamar

1) Ballion

Pesana

mis

a Tas voucher
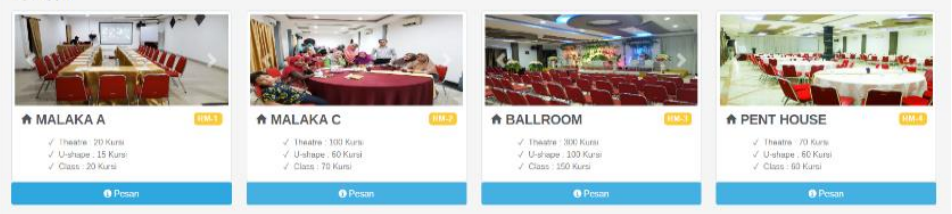

a

Type here to search
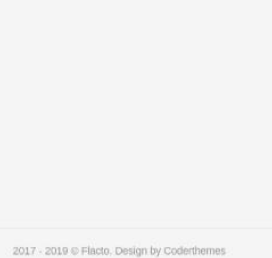

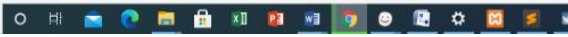

Gambar 13 Implementasi Halaman Ballroom

\section{KESIMPULAN}

Berdasarkan hasil penelitian yang telah dilakukan oleh peneliti, maka dapat diambil kesimpulan bahwa Sistem Informasi Customer Relationship Management pada Hotel Grand Malaka Ethical Palembang Berbasis Web yang telah dibangun mengguankan metode pengembangan prototype dan menggunakan bahasa pemprograman PHP dengan menerapkan framework Codelgniter telah melalui uji coba (testing) dan mulai akan diimplementasikan oleh pihak hotel pada tahun 2021. Dengan dibangunnya Sistem Informasi Customer Relationship Management ini, mempermudah proses pemesanan kamar dan ballroom, mempermudah dalam memberikan informasi yang lebih detail pada customer yang datang langsung ke hotel untuk menanyakan kamar atau ballroom, pihak hotel juga dapat mencari atau melihat laporan dan grafik transaksi pemesanan kamar dan transaksi pemesanan bal/room, dan dengan di bangunnya sistem ini customer disediakan media untuk memberikan masukkan dan keluhan untuk pihak hotel sehingga pihak hotel dapat lebih memahami customer dan bisa terjalin hubungan yang baik antara pihak hotel dengan customer.

\section{DAFTAR PUSTAKA}

[1] B. Suzanto, "Umum Kota Banjar," Pengaruh Kualitas Jasa Pelayanan Terhadap Kepuasan Pasien Pada Rumah Sakit Umum Kota Banjar, vol. 5, 
no. 1, pp. 26-28, 2011.

[2] S. Milwandhari, "Perancangan E-Customer Relationship Management Pada Perusahaan Bidang Jasa Perhotelan," Semassi, vol. 1, no. November, pp. 1-6, 2011.

[3] Z. Libriani, D. Syarif, and W. Nengsih, "E-CRM Pada Hotel Mutiara Merdeka Pekanbaru," vol. Vol.I, No., no. 2, pp. 200-210, 2013.

[4] Sugiyono, Metode Penelitian Kuanititatif, Kualitatif, Dan R\&D. Bandung: Penerbit Alfabet, 2013.

[5] Roger S. Pressman, Rekayasa Perangkat Lunak. Yogyakarta: Penerbit Andi, 2012. 